\title{
Performance Comparison of Doubly Salient Reluctance Generators for High-Voltage DC Power System of More Electric Aircraft
}

\author{
$\mathrm{Li} \mathrm{Yu}$ \\ Center for More-Electric-Aircraft \\ Power System (CMEAPS) \\ Nanjing University of \\ Aeronautics And Astronautics \\ Nanjing, China \\ yulipc@126.com
}

\author{
Zhuoran Zhang \\ Center for More-Electric-Aircraft \\ Power System (CMEAPS) \\ Nanjing University of \\ Aeronautics And Astronautics \\ Nanjing, China \\ apsc-zzr@nuaa.edu.cn
}

\author{
David Gerada \\ Power Electronics, Machines and \\ Control Group (PEMC) \\ University of Nottingham \\ Nottingham, UK \\ david.gerada@nottingham.ac.uk
}

\author{
Chris Gerada \\ Power Electronics, Machines and \\ Control Group (PEMC) \\ University of Nottingham \\ Nottingham, UK \\ chris.gerada@nottingham.ac.uk
}

\begin{abstract}
The generation performance of the switched reluctance machine (SRM)-based starter/generator (S/G) and the doubly salient electromagnetic machine (DSEM)-based $S / G$ is analyzed and compared in this paper. The topologies, operation principles of the doubly salient electromagnetic generator (DSEG) and the switched reluctance generator (SRG) are introduced and investigated comprehensively. The copper loss and iron loss are analyzed and the loss distribution is discussed. The excitation requirement and output power quality are also compared and analyzed. The DSEG has the advantages of employing a reliable rectifier and a simple control method, while achieving higher generation efficiency and better output power quality. The foresaid reason making it a very promising option for the highvoltage DC (HVDC) power system of the more electric aircraft (MEA).
\end{abstract}

Keywords-doubly salient electromagnetic generator, excitation requirement, high-voltage dc system, switched reluctance machine, starter/generator.

\section{INTRODUCTION}

In the more electric aircraft (MEA), the on-board centralized hydraulic power system and bleed-air system are being replaced with electrical system based on the electronically controlled electromechanical devices, with greatly improved reliability, and maintenance and support potential, as well as the possibility for significant improvements in terms of weight, volume, and system complexity [1].

The variable frequency AC (VFAC) and high-voltage DC (HVDC) networks are both adopted in the MEA [2]. The HVDC system can operate in parallel, and is considered as being more reliable. Furthermore, the system weight can be reduced by removing the auto-transformer rectifier units (ATRUs) [3].

The brushless DC starter/generator $(\mathrm{S} / \mathrm{G})$ is an indispensable component of the HVDC power system for MEA [4]. Without frequency limitations, the brushless DC S/G can operate at high-speeds to achieve relatively high power densities. The brushless DC S/G integrated into the more electric engine (MEE) however faces the challenge of harsh operating environment [4],[5].

The brushless wound-rotor synchronous starter/generator has convenient voltage regulation and reliable de-excitation ability in case of a failure. However, the rotor structure is complicated, especially for the use at higher speeds, and the starting control is also a challenging aspect.

The permanent magnet (PM) starter/generator, albeit benefiting from a high power density has the de-excitation problem under fault condition and risk of the irreversible demagnetization [6].

The switched reluctance machine (SRM) is a doubly salient machine with a simple and reliable structure. There is no PM or winding in the rotor. The SRM-based S/G has good faulttolerant performance and is suitable for high-speed operation [7]. The phases need to be excited in the proper rotor position by turns. Therefore, the controlled power converter and rotor position detection are indispensable during power, which reduces the system reliability. Moreover, the SRM-based system has a low power factor [8].

The doubly salient electromagnetic machine (DSEM) has an independent field winding in the stator, while it inherits the robust rotor structure of the SRM [9]. The reliable diode rectifier and field current regulator are needed for power generation operation. The DSEM-based S/G system adopts a full-bridge converter during starting operation. After engine starting, the full-bridge converter can be reused for other onboard motor drives which functions as a common motor start controller (CMSC) [10]. However, the presence of a field winding also increases the copper loss, which needs careful multi-domain evaluation.

It is worth noting that the power generation principles of the DSEM and SRM-based S/G are different. In addition to rectification and excitation units mentioned above, it is necessary to fully evaluate the performance of both of them. In this paper, the topologies, operation principles of the doubly salient electromagnetic generator (DSEG) and switched reluctance generator (SRG) are comprehensively analyzed and compared, as well as those generation performance of losses, excitation requirement and output power quality. 


\section{DOUBly SALIENT RELUCTANCE GENERATORS}

\section{A. Topologies}

Fig. 1 shows the 12/8-pole SRG and DSEG respectively. The DSEM has the same rotor structure as the SRM. The independent field winding is introduced in the DSEM.

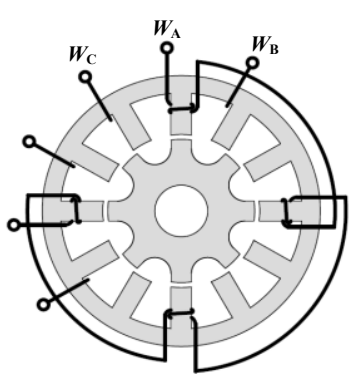

(a)

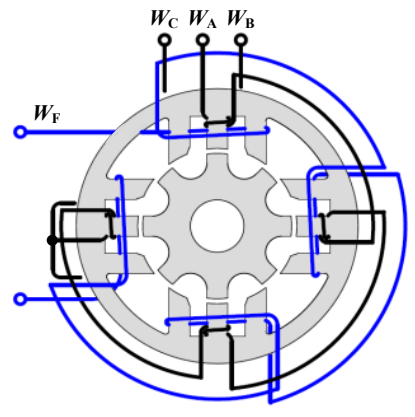

(b)
Fig. 1. Topologies of doubly salient reluctance generators. (a) SRG. (b) DSEG.

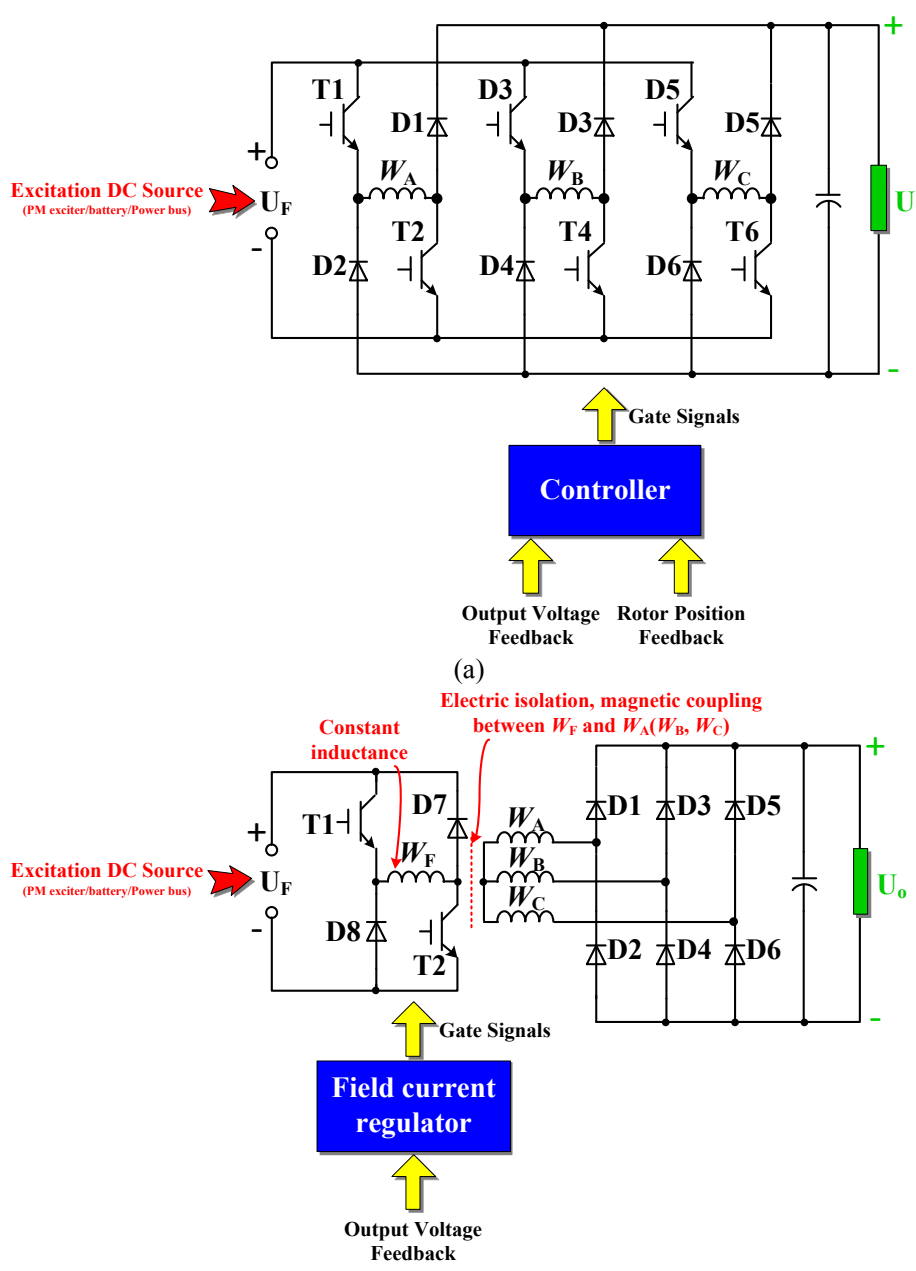

(b)

Fig. 2. Rectifiers and field current regulator connected to doubly salient reluctance generators. (a) Power converter of SRG. (b) Rectifier and field regulator of DSEG.
Fig. 2 shows the topologies of the generation systems. The controlled power converter and rotor position detection are needed for SRG. The generation control is more convenient for the DSEG and is achieved by regulating the DC field current. The field current is relatively small with more field winding turns. The excitation source of both the SRG and DSEG can be the PM exciter and batteries. Self-excitation may also be adopted.

\section{B. Operation Principles}

Fig. 3 shows the phase inductance waveform of the SRG. The phase inductance is variable with the rotor rotation. Fig. 4 shows the field and phase inductance waveforms of the DSEG. It can be seen that the field inductance is almost constant, which facilitates the field current regulation. The phase inductance is also variable with the rotor rotation.

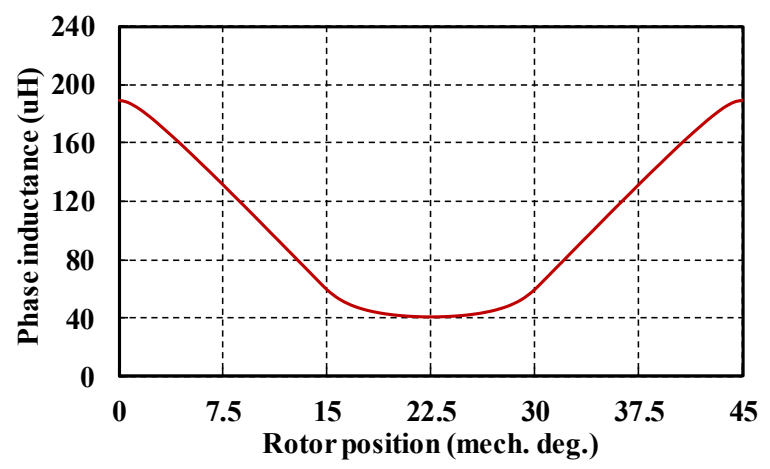

Fig. 3. Phase inductance waveforms of SRG.

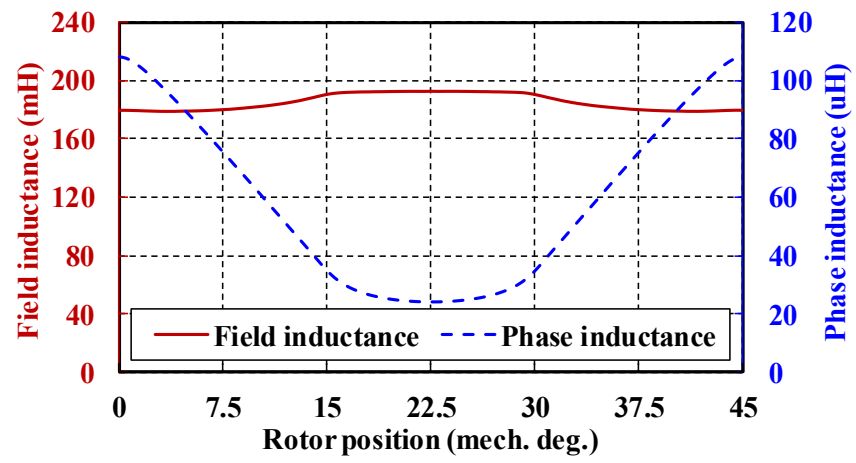

Fig. 4. Inductance waveforms of DSEG.

The operation principle of the SRG is shown in Fig. 5. In mode I, the power switches T1 and T2 are turned on, and the phase current is increased and the corresponding phase is magnetizing. The phase excitation is based on the turn-on angle $\theta_{\text {on }}$ and turn-off angle $\theta_{\text {off }}$, with the conduction angle $\theta_{\text {con }}$ being the interval between them. The position that the stator pole is aligned with the rotor pole is defined as $\theta_{\mathrm{on}}=0^{\circ}$. In mode II, the power switches T1 and T2 are turned off, and the phase current flows through the diodes D1 and D2, thus energy is delivered to the load.

Fig. 6 shows the phase flux linkage and induced emf of the SRG and DSEG respectively. In the SRG, the phase current 
functions as field current during magnetization period. By considering a constant current when magnetizing the SRG, the emf can be estimated by

$$
e=\omega \frac{\partial \psi(\theta, i)}{\partial \theta}
$$

where $\psi$ is the phase flux linkage, and $\omega$ is the angular speed. With phase current increased beyond a certain value, the iron core becomes saturated, and the peak induced emf is held constant or even reduces with the further increase of phase current. In the DSEG, the phases are magnetized by the current in the field winding. The field current of the DSEG is much smaller than the phase current of the SRG.
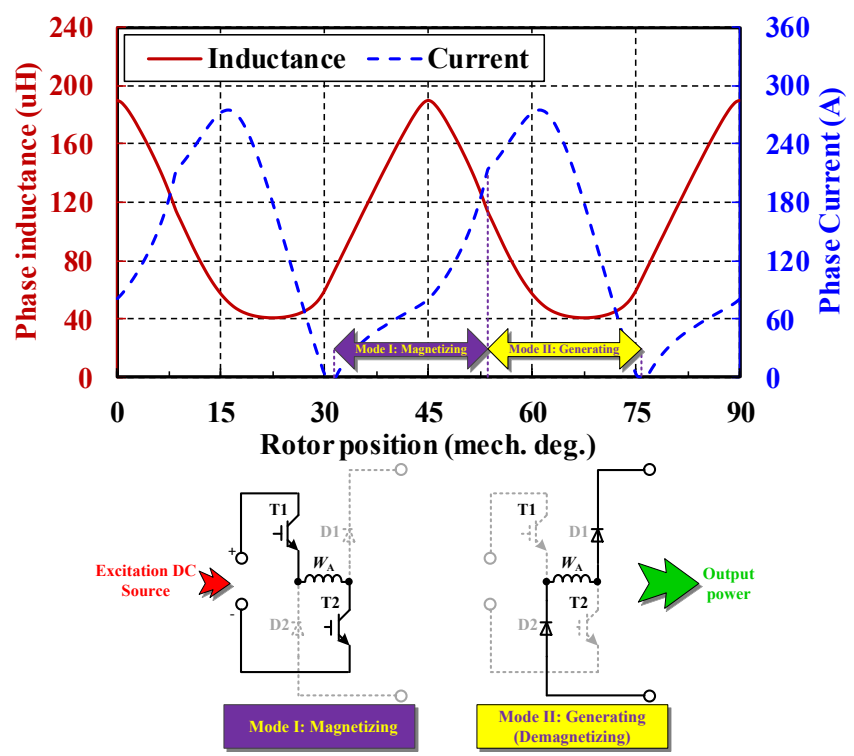

Fig. 5. Typical current waveform and operation modes of SRG for A-phase.

\section{Power Generation Performaces}

Table I lists the key parameters of SRG and DSEG for this comparative analysis. Both of the generators are operated with self-excitation.

TABLE I. KEY PARAMETERS OF SRG AND DSEG

\begin{tabular}{|l|c|c|}
\hline & SRG & DSEG \\
\hline Stator outer diameter $(\mathrm{mm})$ & \multicolumn{2}{|c|}{158} \\
\hline Stator inner diameter $(\mathrm{mm})$ & \multicolumn{2}{|c|}{90} \\
\hline Core length (mm) & \multicolumn{2}{|c|}{120} \\
\hline Number of turns for phase winding per pole & 4 & 3 \\
\hline Total number of turns for field winding & 0 & $100 \times 4$ \\
\hline Speed $(\mathrm{r} / \mathrm{min})$ & \multicolumn{2}{|c|}{36000} \\
\hline Output voltage $(\mathrm{V})$ & \multicolumn{3}{|c|}{270} \\
\hline Ouput power $(\mathrm{kW})$ & \multicolumn{3}{|c|}{40} \\
\hline
\end{tabular}

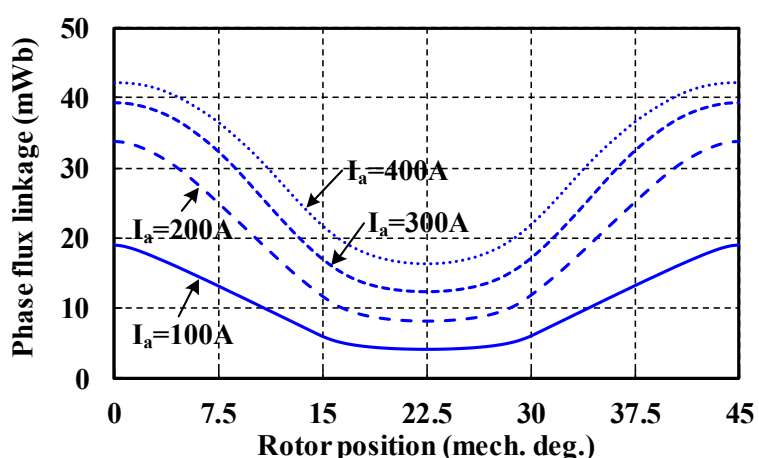

(a)

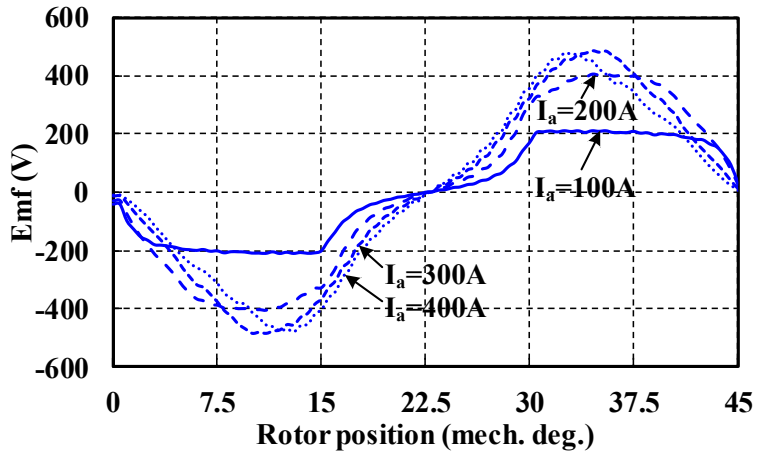

(b)

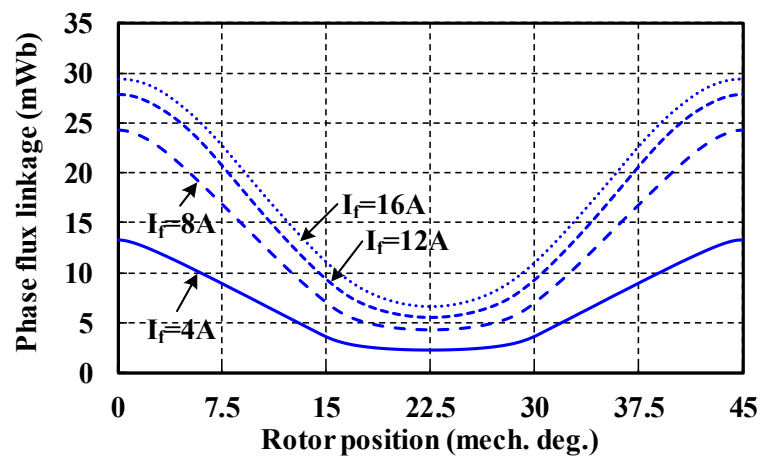

(c)

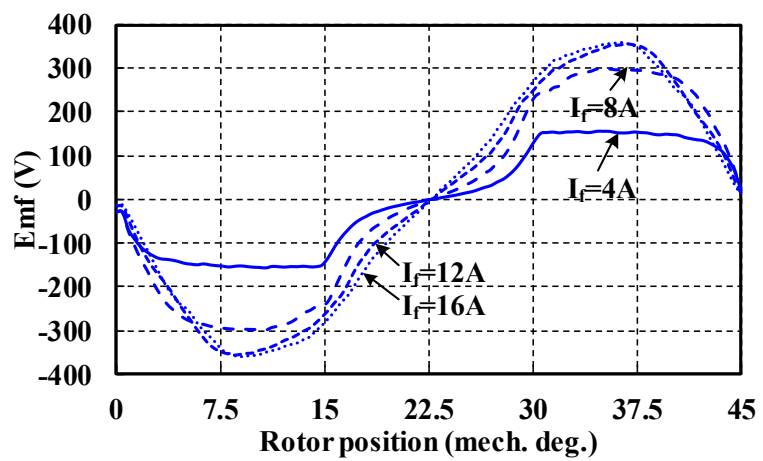

(d)

Fig. 6. Phase flux linkage and emf waveforms. (a) Phase flux linkage waveforms of SRG. (b) Emf waveforms of SRG. (c) Phase flux linkage waveforms of DSEG. (d) Emf waveforms of DSEG.

\section{A. Influence of Excitation Angles on Generation Performance for SRG}

Because of the high operating speed, single-pulse control is 
adopted for the SRG. The excitation angles, that is the turn-on angle and the conduction angle, influence the output performance significantly. Fig. 7 shows the output power and peak phase current versus the excitation angles with $270 \mathrm{~V} \mathrm{DC}$ voltage. The blue pentagram represents the SRG operating at $40 \mathrm{~kW}$ with the minimum peak value of phase current. The turn-on angle is set to $-14^{\circ}$ and conduction angle is set to $22^{\circ}$. Fig. 8 shows the phase current waveforms with different turnon angles for the same output power level of $40 \mathrm{~kW}$. It can be seen that the phase current is increased fast when the rotor pole is sliding off the stator pole during the magnetization with $\theta_{\mathrm{on}}=-7.5^{\circ}$ since the phase inductance is lower and the emf is negative.

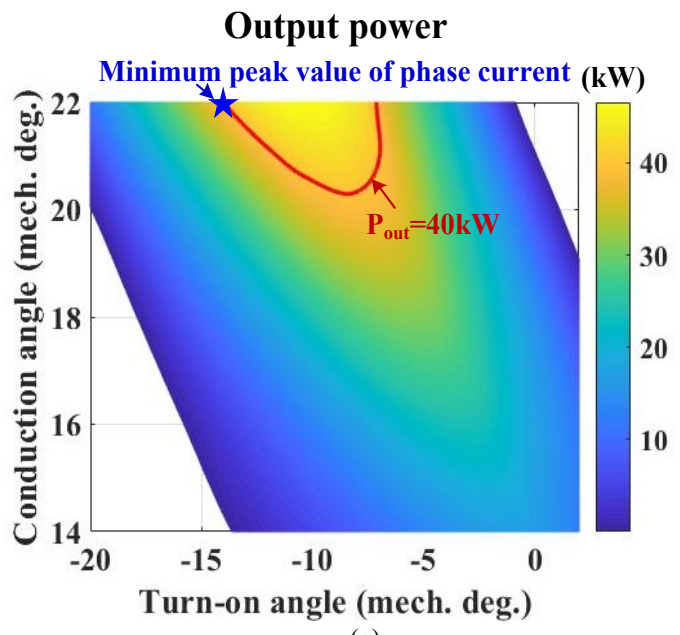

(a)

Peak value of phase current

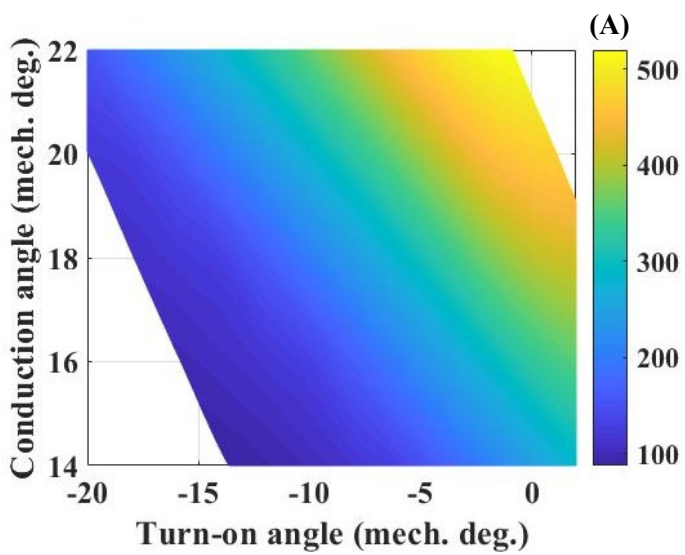

(b)

Fig. 7. Output power, copper loss and peak value of phase current versus turn-on angle and conduction angle $\left(\mathrm{U}_{\mathrm{o}}=270 \mathrm{~V}, \mathrm{n}=36000 \mathrm{r} / \mathrm{min}\right)$. (a) Output power. (b) Peak value of phase current.

It should be noted that although the proper excitation angle can improve the power generation performance of the SRG, the feature of multiple control variables also increases the difficulty of control.

\section{B. Influence of Field Current on Generation Performance for DSEG}

Fig. 9 shows the influence of the field current on the output power considering the consumed field power. The copper loss including both the field copper loss as well as the armature copper loss. It can be seen that the DSEG is able to maintain the constant voltage over a wide range of load variations, only by field regulation. Due to the asymmetric flux path of each phase, the phase currents of the DSEG are unbalanced. The peak phase current of the DSEG is lower than that of the SRG as shown in Fig. 8.

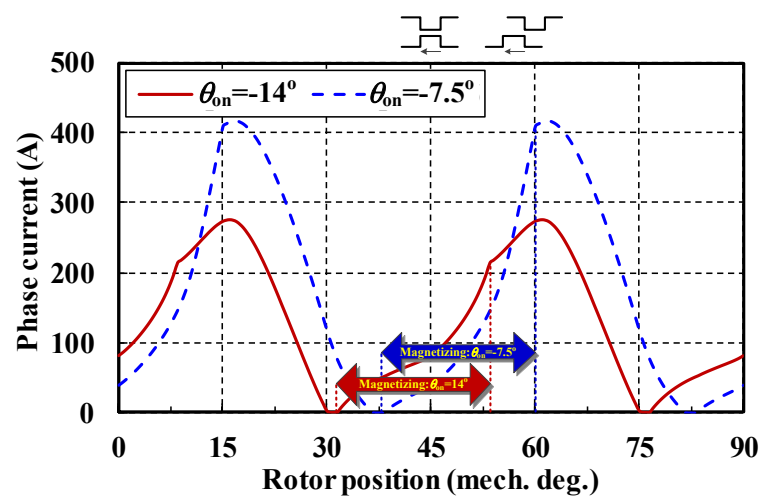

Fig. 8. Phase current waveforms of $\mathrm{SRG}\left(\theta_{\text {con }}=22^{\circ}, \mathrm{U}_{\mathrm{o}}=270 \mathrm{~V}, \mathrm{P}_{\text {out }}=40 \mathrm{~kW}\right.$, $\mathrm{n}=36000 \mathrm{r} / \mathrm{min}$ ).

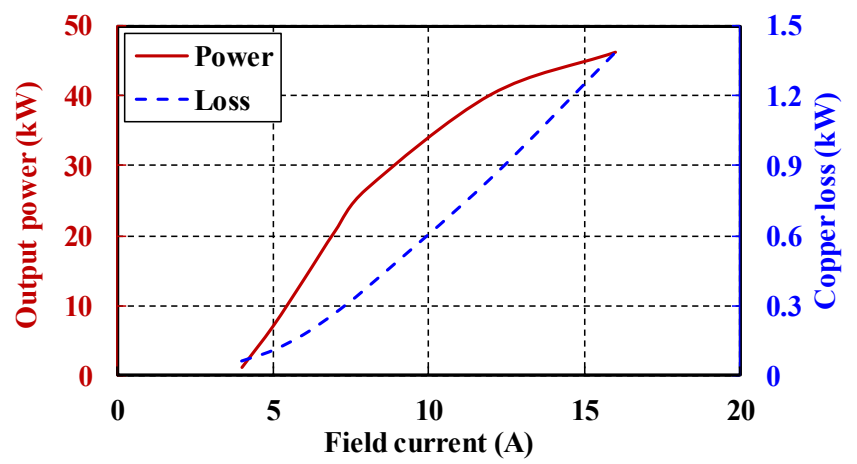

Fig. 9. Output power and copper loss versus field current $\left(\mathrm{U}_{\mathrm{o}}=270 \mathrm{~V}\right.$, $\mathrm{n}=36000 \mathrm{r} / \mathrm{min}$ ).

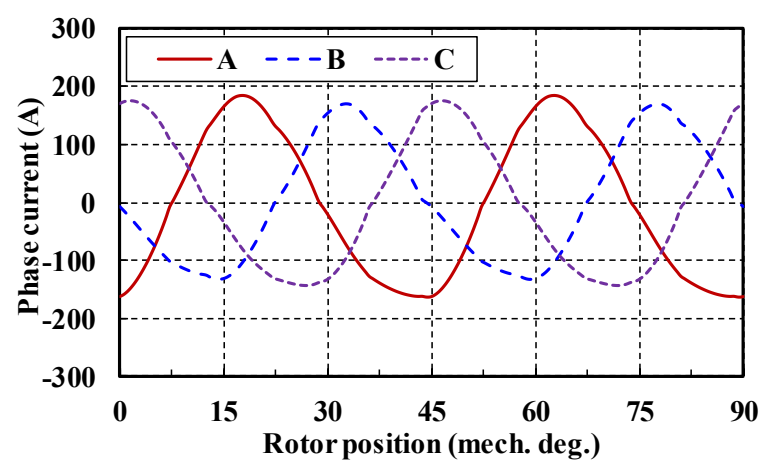

Fig. 10. Phase current waveforms of DSEG $\left(U_{0}=270 \mathrm{~V}, P_{\text {out }}=40 \mathrm{~kW}\right.$, $\mathrm{n}=36000 \mathrm{r} / \mathrm{min}$ ).

\section{COMParative Study}

\section{A. Copper and Iron Loss}

Fig. 11 shows the copper losses and iron losses of SRG and 
DSEG. The higher armature copper loss is produced in SRG because the phase current takes on additional excitation functions. The stator iron loss of the SRG is evidently more than that of the DSEG. Overall, the SRG produces more loss than the DSEG.

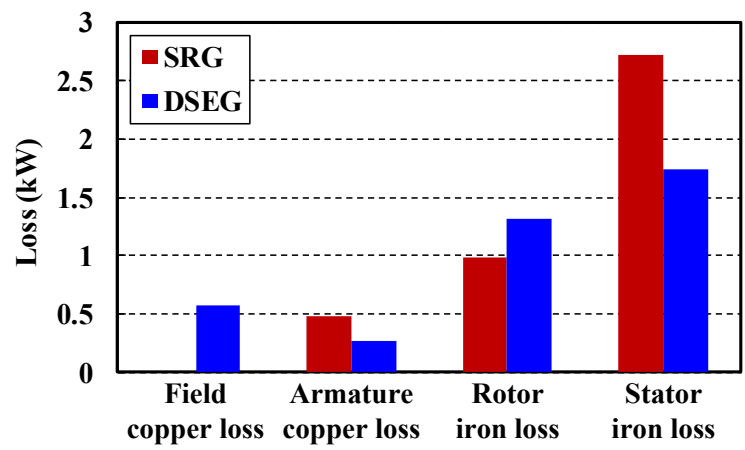

(a)

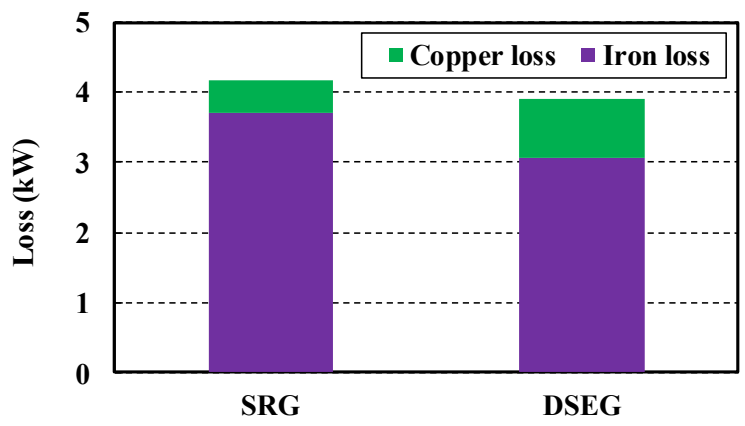

(b)

Fig. 11. Copper and iron loss $\left(\mathrm{U}_{\mathrm{o}}=270 \mathrm{~V}, \mathrm{P}_{\text {out }}=40 \mathrm{~kW}, \mathrm{n}=36000 \mathrm{r} / \mathrm{min}\right)$. (a) Loss breakdown. (b) Total loss.

\section{B. Excitation Requirement}

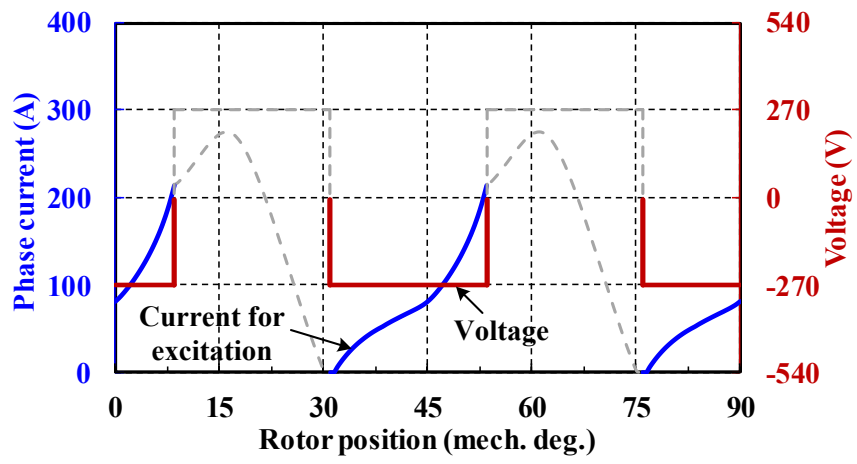

Fig. 12. Phase current and phase voltage during excitation of $S R G\left(U_{0}=270 \mathrm{~V}\right.$, $\left.\mathrm{P}_{\text {out }}=40 \mathrm{~kW}, \mathrm{n}=36000 \mathrm{r} / \mathrm{min}\right)$.

The excitation requirement of the SRG is significant, because the excitation energy is lost during each cycle to the load as shown in Fig. 12. When the external excitation source is used, a part of excitation energy is delivered to the load through the freewheeling diodes, as shown in Fig. 13. The excitation power of the DSEG which is equal to the copper loss in field winding is only $0.58 \mathrm{~kW}$. For the $\mathrm{SRG}$, this is undesirable, in that a significant excitation source is required to supply this excitation power. Therefore, self-excitation is adopted for the SRG to eliminate the need for this significant excitation which, however, increases the ripple of the output voltage.

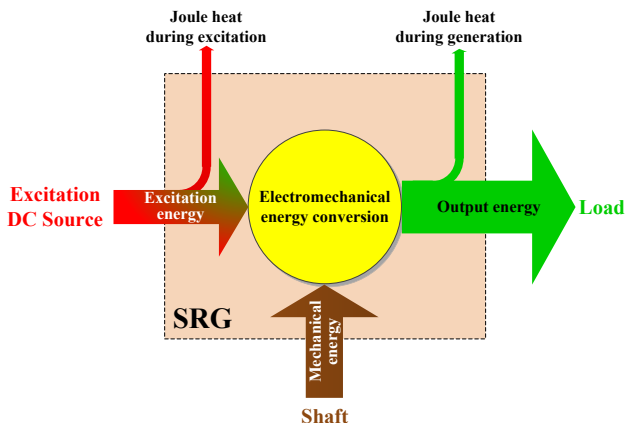

(a)

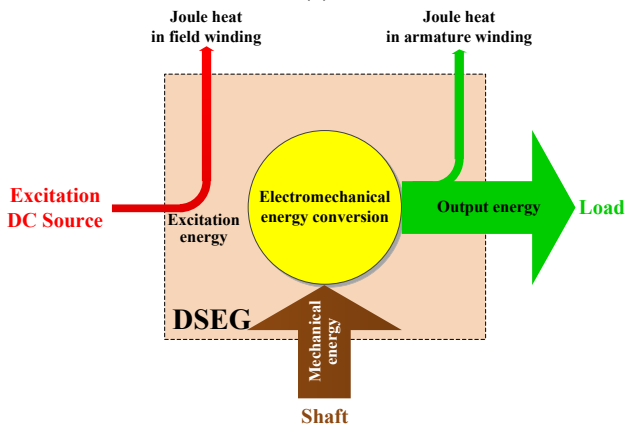

(b)

Fig. 13. .Energy flow diagram. (a) SRG. (b) DSEG.

\section{Ripple}

Fig. 14 shows current in the DC-link filter capacitor with self-excitation. It can be seen that the SRG has the evident current ripple due to significant excitation power. The current ripple results in an increase of the capacitor size and weight, both of which are highly undesirable given the goals of the application in hand.

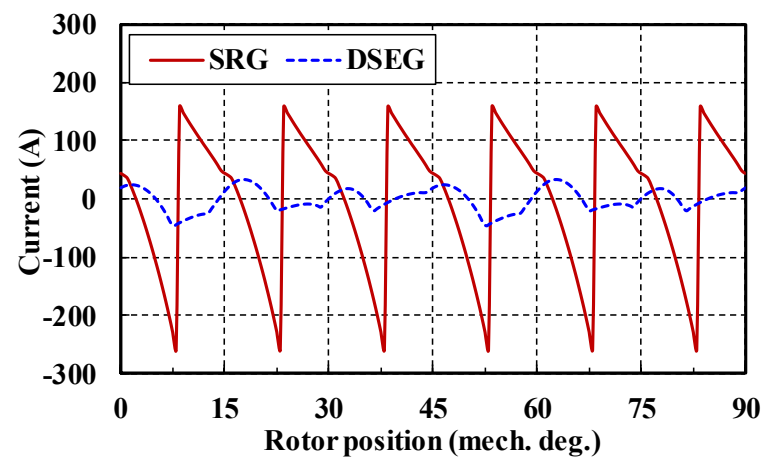

Fig. 14. Current ripple in DC-link filter capacitor $\left(\mathrm{U}_{\mathrm{o}}=270 \mathrm{~V}, \mathrm{P}_{\text {out }}=40 \mathrm{~kW}\right.$, $\mathrm{n}=36000 \mathrm{r} / \mathrm{min}$ ).

\section{CONCLUSION}

This paper gives an in-depth comparative analysis of the generation performance of the SRM-based S/G and DSEMbased $\mathrm{S} / \mathrm{G}$ for the MEA HVDC power system. The DSEG 
leads to a more reliable system structure and a simple control method. The additional copper loss exists in the field winding of the DSEG. For high-speed operation, the total loss of the DSEG is lower than that of the SRG due to lower stator iron loss. The SRG has significant excitation power and selfexcitation is adopted to eliminate the need for the significant excitation, yet leading to larger, heavier capacitors. It can be concluded that the DSEM-based $\mathrm{S} / \mathrm{G}$ is a promising option for the MEA HVDC power system.

\section{ACKNOWLEDGMENT}

This work was supported in part by the National Natural Science Foundation for Excellent Young Scholar of China under Award 51622704, in part by Jiangsu Provincial Science Funds for Distinguished Young Scientists under Award BK20150033, and in part by Funding for Outstanding Doctoral Dissertation in NUAA under Project BCXJ15-01.

\section{REFERENCES}

[1] P. Wheeler and S. Bozhko, "The More Electric Aircraft: Technology and challenges," IEEE Electrification Magazine, vol. 2, no. 4, pp. 6-12, Dec. 2014.

[2] B. Sarlioglu and C. T. Morris, "More Electric Aircraft: Review, Challenges, and Opportunities for Commercial Transport Aircraft," IEEE Transactions on Transportation Electrification, vol. 1, no. 1, pp.
54-64, June 2015.

[3] X. Roboam, B. Sareni, and A. De Andrade, "More electricity in the air: Toward optimized electrical networks embedded in more-electrical aircraft," IEEE industrial electronics magazine, vol. 6, pp. 6-17, 2012.

[4] G. M. Raimondi et al., "Aircraft embedded generation systems," 2002 International Conference on Power Electronics, Machines and Drives (Conf. Publ. No. 487), 2002, pp. 217-222.

[5] M. J. Provost, "The More Electric Aero-engine: a general overview from an engine manufacturer," 2002 International Conference on Power Electronics, Machines and Drives (Conf. Publ. No. 487), 2002, pp. 246251.

[6] Z. Zhang, J. Huang, Y. Jiang, W. Geng and Y. Xu, "Overview and analysis of PM starter/generator for aircraft electrical power systems," CES Transactions on Electrical Machines and Systems, vol. 1, no. 2, pp. 117-131, 2017

[7] J. Borg Bartolo, M. Degano, J. Espina and C. Gerada, "Design and Initial Testing of a High-Speed 45-kW Switched Reluctance Drive for Aerospace Application," IEEE Transactions on Industrial Electronics, vol. 64, no. 2, pp. 988-997, Feb. 2017.

[8] A. V. Radun, C. A. Ferreira and E. Richter, "Two-channel switched reluctance starter/generator results," IEEE Transactions on Industry Applications, vol. 34, no. 5, pp. 1026-1034, Sep/Oct 1998.

[9] Z. Zhang, L. Yu, Y. Wang, Y. Wang and Y. Yan, "Overview and design methodology of doubly salient brushless dc generators with stator-field winding," IET Electric Power Applications, vol. 11, no. 2, pp. 197-211, 22017.

[10] Stephen. Clark, "787 Propulsion System," [Online] Available: http://www.boeing.com/commercial/aeromagazine/articles/2012 q3/2/ Accessed: May 2018. 